O Open Access Full Text Article

REVIEW

\title{
Descemet membrane endothelial keratoplasty (DMEK): an update on safety, efficacy and patient selection
}

This article was published in the following Dove Press journal:

Clinical Ophthalmology

\author{
Bruno Lovaglio Cançado \\ Trindade ${ }^{1-3}$ \\ Glauber Coutinho Eliazar ${ }^{3,4}$ \\ 'Cançado Trindade Eye Institute, Belo \\ Horizonte, Brazil; ${ }^{2}$ Medical Science \\ School of Medicine - FELUMA, Belo \\ Horizonte, Brazil; ${ }^{3}$ Cornea Department, \\ Medical Sciences University Hospital Eye \\ Institute, Belo Horizonte, Brazil; ${ }^{4}$ Cornea \\ Department, Santa Casa Eye Clinic, Belo \\ Horizonte, Brazil
}

\begin{abstract}
Descemet membrane endothelial keratoplasty (DMEK) is gaining popularity worldwide as a procedure to address corneal endothelial dysfunctions. Its perfect anatomical result improves outcomes and expedites visual recovery. This review addresses important aspects of safety, efficacy and patient selection.
\end{abstract}

Keywords: descemet membrane endothelial keratoplasty (DMEK), complications, safety, indication, patient selection

\section{Introduction}

In the last two decades, the treatment of corneal endothelium diseases underwent a significant revolution. What was previously treated with full-thickness corneal transplants is now managed with a more selective approach with the use of endothelial keratoplasty. Even with the early techniques, clinical outcomes and lower risk of complications were already promising in comparison to the standard penetrating keratoplasty (PK). ${ }^{1-5}$ The use of a selective endothelium replacement enabled surgeons to maintain the ocular surface intact and decrease wound sizes, thus expediting visual recovery. It also eliminated the open-sky step during surgery and any suture-related complications, minimizing risks. ${ }^{5}$ Moreover, with the evolution of the technique, numerous other advantages were noted such as a better refractive result, less induction of higher-order aberrations, faster visual rehabilitation, lower rejection rate, less use of topical steroids and chance of secondary glaucoma as well as decrease in surgical cost. Because of all these advantages, endothelial keratoplasty has become the procedure of choice for endothelial corneal diseases. The Eye Bank Association of America Statistical Reports have shown an increase in adoption of endothelial keratoplasties since very early after its introduction in 2009, and it has been the most performed technique for all corneal transplants in the USA since $2011 .^{6}$

Melles et al first proposed the substitution of the deeper lamellas of the stroma together with Descemet's membrane and endothelium in a procedure that was named deep lamellar endothelial keratoplasty (DLEK). ${ }^{1}$ The surgical challenges involved in preparing the recipient cornea precluded its wider adoption. However, with the introduction of Descemet's membrane stripping, the procedure became much easier to be performed and surgeons started their transition to endothelial grafting. This technique was named Descemet stripping endothelial keratoplasty (DSEK). However, the
Correspondence: Bruno Lovaglio Cançado Trindade

Cançado Trindade Eye Institute, Rua Manaus, 595, 30.150-350 Belo Horizonte, MG, Brazil

Tel +55 3 I3 24I 5544

Email bruno.trindade@ioct.org 
preparation of the donor cornea was still being done manually and involved dissection of the posterior stroma with the cornea mounted on an artificial anterior chamber. When Gorovoy proposed the use of a microkeratome to facilitate the preparation of the donor tissue, the harvesting of the endothelial lamella became much safer and more reproducible and this surgery gained a global popularity. ${ }^{7}$ It was named Descemet stripping automated endothelial keratoplasty (DSAEK). These techniques proved their superiority when compared to PK. ${ }^{8}$

In 2006, Melles et al introduced the Descemet membrane endothelial keratoplasty (DMEK). ${ }^{4}$ This is a procedure that aimed for a perfect substitution of the endothelial layer of the cornea using only Descemet membrane as a carrier. DMEK eliminated the stromal interface, allowing perfect anatomical replacement of the diseased endothelium by a healthy donor. ${ }^{9,10}$ In their original paper, they reported visual acuities never before imagined after a corneal transplant. With patients achieving 20/20 vision a few days after surgery, DMEK has attracted the attention of the global corneal surgeons since its introduction. However, the challenges of the preparation of the donor tissue and the surgical difficulties of unscrolling the endothelial lamella inside the eye made the transition to this procedure not so straightforward. In fact, increased global adoption of DMEK did not occur until 2010 with the standardization of the technique and evolution of the knowledge involved in the procedure. ${ }^{11}$ Donor corneal preparation is already a reality in several eye banks, and a pre-peeled, pre-cut, pre-stamped, pre-stained and even pre-loaded tissue can now be provided for the surgeon. ${ }^{12}$ This "patient-ready tissue" can facilitate the DMEK learning curve.

\section{Safety}

One of the most important aspects of lamellar endothelial grafts is the fact that it is overall a safer procedure. By eliminating open-sky surgical time, suture-related complications and decreasing the wound size, the main sight-threatening complications involved in penetrating keratoplasties were eliminated.

However, there are specific complications that are associated with this new procedure. We will group the main ones into intraoperative, early-postoperative and late-postoperative to facilitate comprehension.

\section{Intraoperative complications}

There are many intraoperative complications exclusively to DMEK.
Inadvertent graft injection into the posterior chamber or vitreous cavity can occur especially in cases in which the anterior chamber anatomy is distorted, when there is a large pupil or iris defect, when there is zonular dehiscence or in aphakia. In such cases, DSAEK may be preferable to DMEK.

Another possible complication is the accidental ejection of the graft from inside the anterior chamber through one of the incisions. This can happen especially when manipulating the main or sideport incisions with the intraocular pressure elevated. Once the graft is injected in the eye, care should be taken to avoid burping fluid through the main incision to minimize the risk of graft ejection. Another solution is to place a suture in the main incision after graft insertion.

Loss of graft staining can also happen in cases in which graft unfolding lingers. This can be especially challenging when dealing with an opaque cornea. Restaining of the graft with trypan blue can be achieved, but it should only be attempted in small aliquots to avoid staining the bare stromal surface and obscuring visualization even more. Indirect or oblique illumination with the vitrector light pipe or an external light source can also be tried to improve visualization in these cases.

Anterior chamber bleeding and fibrin formation during graft unscrolling may interfere with proper maneuvers and avoid an ideal graft placement. This complication may occur after intraoperative peripheral iridectomy, inadvertent iris trauma and hypotony-related angle bleeding, among other scenarios. This complication is best managed by quickly opening the graft and tamponading the bleeding with a full air/gas chamber fill.

\section{Early postoperative complications}

An initial complication noted in endothelial keratoplasties was graft detachment. Since no sutures were being used to secure the graft, an air or gas bubble had to be inserted in the anterior chamber to fixate the graft in place. The lack of adequate support of improper positioning resulted in graft detachments. With the introduction of DMEK, the thinner tissue was reported to have even higher rates of detachment when compared to DSAEK. The incidence of graft detachment in DMEK varies significantly in the literature, with rates reported as high as $74 \%$. Most of these are peripheral detachment in which it is known that spontaneous resolution occurs most of the time. ${ }^{13}$ However, detachments involving over one-third of the 
graft or involving the central cornea may be preferably treated with a rebubble (Figure 1).

This is a procedure that can be performed either at the slit lamp or under the operating microscope. ${ }^{14}$ A single rebubble procedure is successful in the vast majority of times. It is also important to mention that partial graft detachment may lead to a decrease in endothelial cell count (ECC) and consequently shorter transplant survival. ${ }^{15}$ Total graft detachment may also occur and the graft may rescroll inside the anterior chamber (Figure 2).

It may be challenging to unscroll it once the staining has been washed away and visualization deteriorated. This situation may be better treated with a regraft.

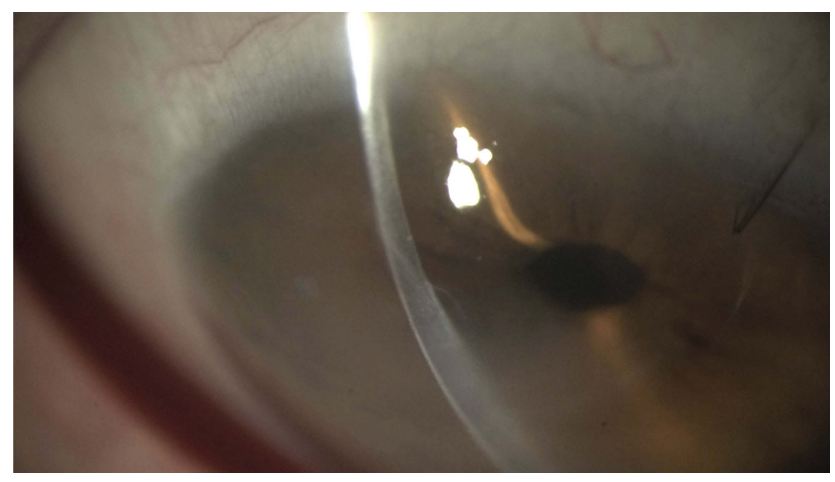

Figure I Note central DMEK graft detachment with corneal edema. Abbreviation: DMEK, descemet membrane endothelial keratoplasty.
The second most common DMEK complication is immediate postoperative ocular hypertension, with frequency ranging between $0.5 \%$ and $12.5 \%{ }^{16-18}$ For $80 \%$ of these patients, the ocular hypertension is due to an early pupillary blocking by the air bubble (Figure 3) and 20\% secondary to air passage to the posterior chamber (Figure 4).

To avoid this complication, there are strategies like creating a peripheral iridotomy and leaving an incomplete anterior chamber air/gas filling (close to $80 \%$ ) at the end of surgery.

\section{Late postoperative complications}

Primary graft failure in DMEK occurs when the graft is well positioned, but the cornea does not clear. It is relatively rare, ranging $0-8.2 \%$ in the literature. ${ }^{16,19-22}$ This complication may be related to intrinsic tissue conditions but may also be secondary to surgical trauma or an upside-down implantation. The best time for a new transplant is unknown, but it is advised to control inflammation and improve corneal transparency as much as possible before proceeding with the new surgery.

Allograft rejection is a major concern in all types of corneal transplantation. It has been shown that DMEK has a remarkable low incidence of graft rejection. This is especially true when compared to DSAEK or PK. Anshu et al demonstrated a significantly less risk of a rejection episode with DMEK when compared to DSAEK or PK. The DMEK grafted eyes had a 15 -fold decrease in risk of having endothelial rejection when

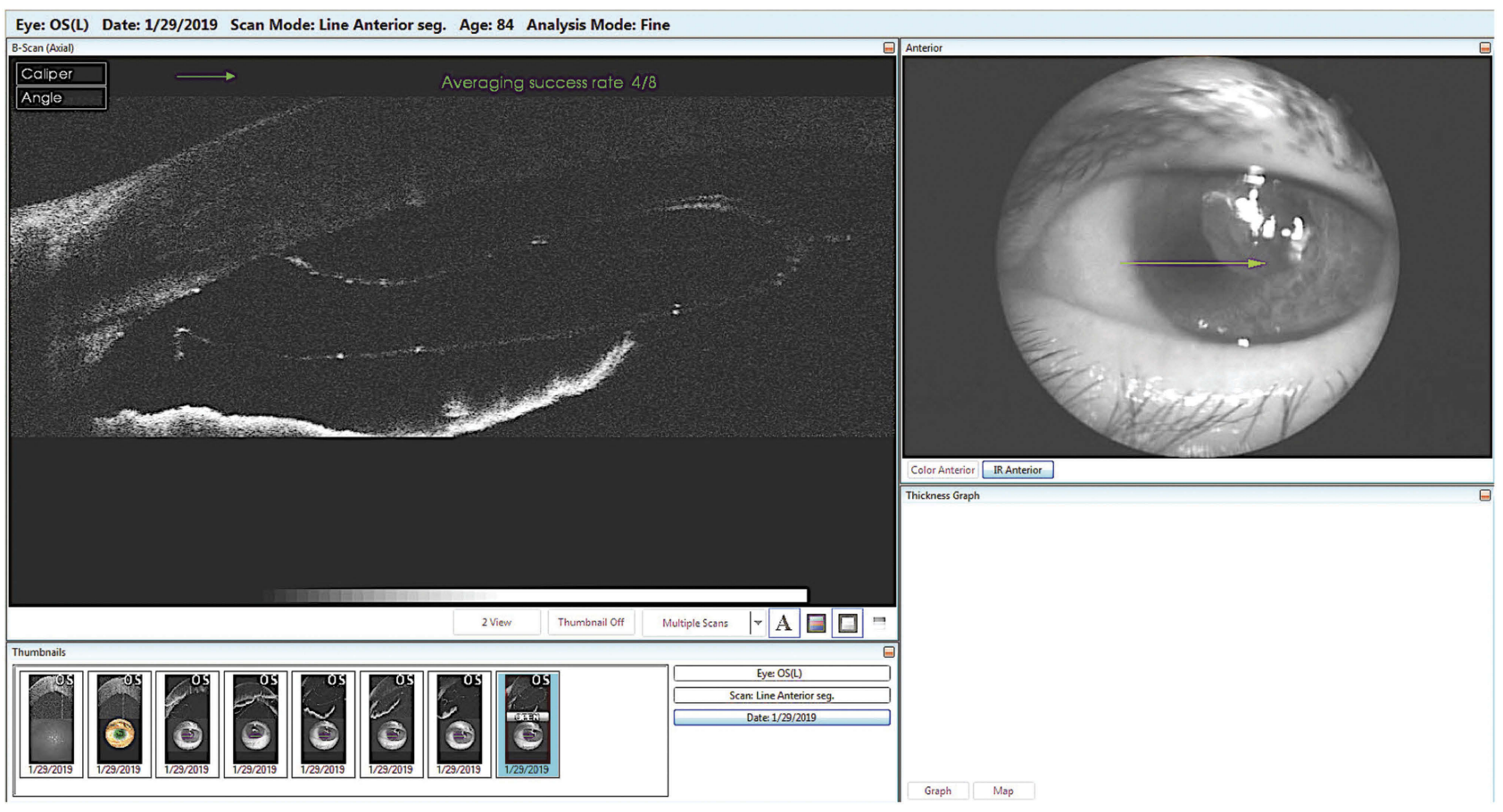

Figure 2 AS-OCT showing a complete graft detachment with graft rescrolling at the anterior chamber angle. 


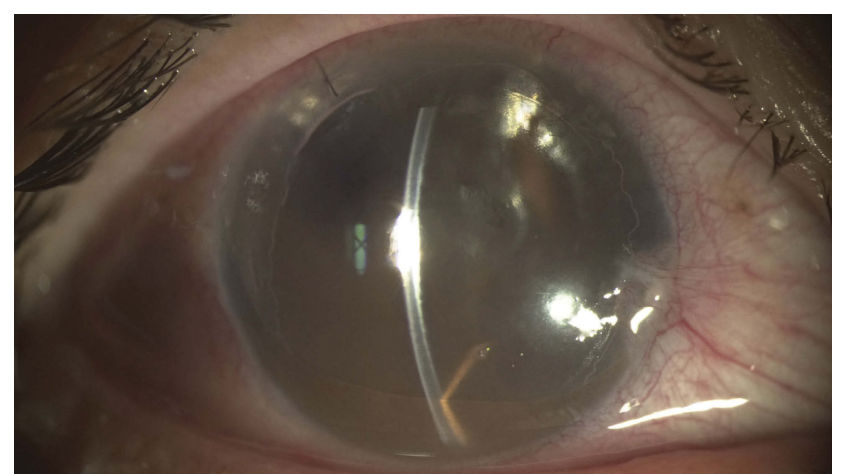

Figure 3 Pupillary block caused by the air bubble.

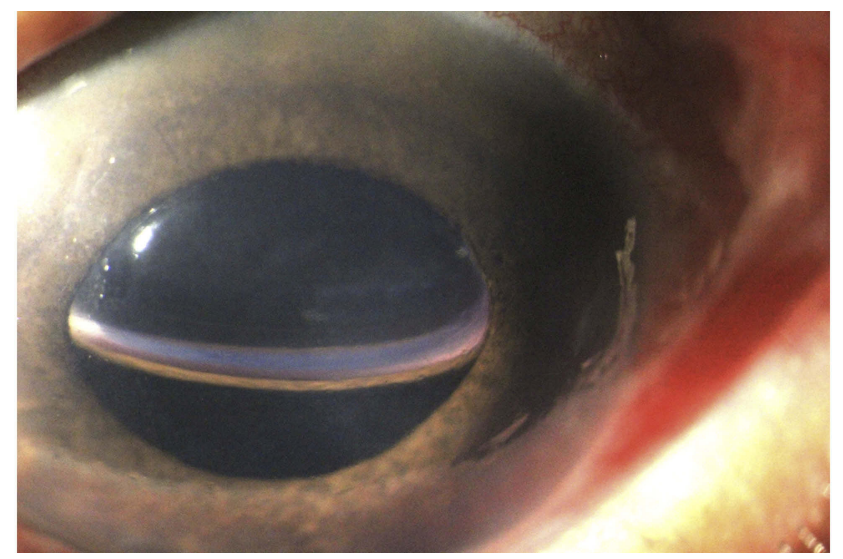

Figure 4 Note the displacement of the air bubble to the posterior chamber.

compared to DSAEK and a 20 times less risk when compared to $\mathrm{PK}^{23}$ Prolonged steroid use has been demonstrated to decrease the risk of immune rejection even more. Even a low-dose scheme, such as once a day, of a weak topical steroid has been shown to have a protective effect, lowering the incidence of graft rejection even further. ${ }^{24}$

Endothelial keratoplasty was initially limited to pseudophakic eyes due to a deeper anterior chamber in these cases. In cases in which a crystalline lens was present even without opacification, cataract surgery was performed, and many studies have shown the safety of combining these two procedures. With the evolution of the technique and the fact that DMEK uses a thinner tissue, some studies have shown the benefit and safety of performing DMEK in phakic eyes without removing the crystalline lens. This is especially important in younger patients in which accommodation is still present. There have also been some reports showing the safety of performing cataract surgery in these eyes after having had a DMEK graft although further loss of endothelial cells and graft failure might be a concern. ${ }^{25,26}$
There is a significant learning curve in DMEK compared to other types of corneal transplants. The greatest difficulties are related to the preparation of the donor graft, its insertion in the anterior chamber and opening with correct orientation and proper centration. ${ }^{16}$ Even with these challenges, there is evidence that improvement of the visual acuity, loss of endothelial cells and other complication rates are reasonably good since the beginning of the learning curve. ${ }^{27}$

Recent meta-analysis has summarized different aspects about the safety and outcomes of DMEK in comparison to DSAEK, highlighted in Table $1 .^{28-32}$

\section{Efficacy}

DMEK provides an average of best-corrected visual acuity (BCVA) of $20 / 25$ in $50-80 \%$ of the cases at 6 months. ${ }^{21}$ In a recent series involving patients with Fuchs endothelial dystrophy, after 24 months, $53 \%$ of the DMEK eyes achieved BCVA of $20 / 25$. This same level of vision was achieved only in $15 \%$ of the DSAEK eyes and $10 \%$ of the PK cases. ${ }^{21}$ Besides the improved BCVA in DMEK due to the lack of stromal interface, this technique also provides a faster vision recovery. In only 4 months, $50 \%$ of the patients reached $20 / 40$ or better after a DMEK, while it may take significantly longer after DSAEK or PK to achieve a similar acuity. ${ }^{21,33,34}$ (Figure 5)

The underlying pathology also contributes to some variation in results. The overall rates for ECC, central corneal thickness (CCT), complications and visual rehabilitation process are generally better for Fuchs endothelial corneal

Table I Comparison between DMEK and DSAEK regarding main differences

\begin{tabular}{|l|l|l|}
\hline & DMEK & DSAEK \\
\hline $\begin{array}{l}\text { Faster visual recovery } \\
\text { Better visual outcome }\end{array}$ & $\mathrm{X}$ & \\
$\begin{array}{l}\text { Lower immune } \\
\text { rejection rate }\end{array}$ & $\mathrm{X}$ & \\
$\begin{array}{l}\text { Less refractive error } \\
\text { ECC loss }\end{array}$ & $\mathrm{X}$ & \\
$\begin{array}{l}\text { Primary and secondary } \\
\text { graft failure rate } \\
\text { Complications during } \\
\text { and after surgery } \\
\text { Less technically } \\
\text { challenging }\end{array}$ & Same & Same \\
Rebubble rate & & Same \\
& $\begin{array}{l}\text { May be higher (especially on } \\
\text { initial learning curve) }\end{array}$ & \\
\hline
\end{tabular}

Abbreviations: DMEK, descemet memebrane endothelial keratoplasty; DSAEK, descemet stripping automated endothelial keratoplasty; ECC, endothelial cell count. 


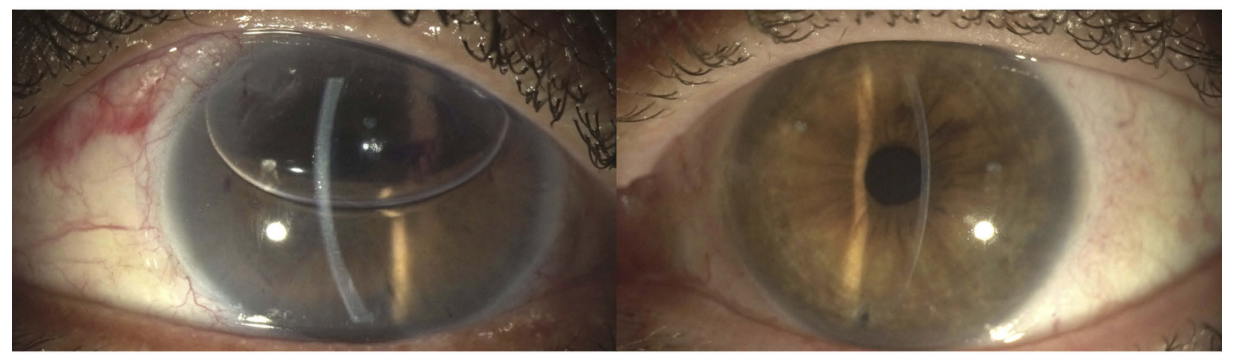

Figure 5 Early (left) and late (right) post DMEK transplantation. Note the perfect anatomical replacement of this procedure. Abbreviation: DMEK, descemet membrane endothelial keratoplasty.

dystrophy (FECD) than for pseudophakic bullous keratopathy (PBK).

Regarding endothelial cell loss rate, there is no difference comparing DMEK, DSAEK and PK at 6 months, with 34.7$47 \%$ of the cell loss. However, the rate of loss is initially faster in lamellar transplants, probably due to increased manipulation and trauma at graft insertion. ${ }^{11,16,20,26,35-38}$

A meta-analysis comparing DMEK and DSAEK concluded that both procedures have the same complication rates in graft detachment, graft failure and rejection, although DMEK showed better visual outcome and patient satisfaction. ${ }^{39}$ Ultra-thin DSAEK is claimed to have similar results to DMEK. Since this study did not compare different DSAEK graft thicknesses, one cannot make any conclusion, even though there are arguments that ultra-thin DSAEK may be as good as DMEK. ${ }^{40}$

Refractive predictability is another major advantage of DMEK due to preservation of anterior and posterior corneal surfaces. Usually, there is a postsurgical hypermetropic shift of approximately $+0.50 \mathrm{D}$. When performing combined surgery with cataract, biometric calculation with a final target of -0.50 to $-1.00 \mathrm{D}$ is recommended. ${ }^{27,38,41-43}$ DMEK can also be considered in patients with a history of laser vision correction or phakic IOL implantation. ${ }^{4,45}$ Due to its high refractive accuracy, there have been reports of successfully combining DMEK with toric or even multifocal IOL implantation. However, studies showing the safety and effectiveness of this combination are still lacking. It is also known that higher-order aberrations, although improved by surgery, may still compromise visual function when comparing to healthy controls. ${ }^{46}$

DMEK technique allows the use of donor corneas with compromised corneal layers but with a healthy endothelium, increasing the number of corneas available for transplantation. It is also possible to use the same donor cornea to two patients, one for endothelial transplantation and another for anterior lamellar, for example. In an attempt to further increase the number of patients benefited with a limited number of donated corneas, techniques have also been described to use half or even one-fourth of the donor graft per patient, procedures called hemi- and quarter-DMEK. ${ }^{47-51}$

\section{Patient selection}

Endothelial dystrophies such as Fuchs' and posterior polymorph, bullous keratopathy (pseudophakic or aphakic) and endothelial decompensation (post-traumatic or postsurgery, such as glaucoma tubes and stents) are candidates for endothelial transplantation. ${ }^{44}$ Endothelial failure of previous PK or even cases of Iridocorneal Endothelial (ICE) syndrome have already been reported as been successfully treated with DMEK. ${ }^{52,53}$

Contraindications include situations in which opacities or stromal scars may limit vision during surgery or in the postoperative period. Even in situations of primary endothelial disease, chronic edema can lead to stromal fibrosis and the posterior lamellar transplant might not be ideal. In those situations, a PK may be considered. Aphakia is also a relative contraindication and may lead to losing the graft to the posterior cavity. Vitrectomized eyes are challenging because of the difficulties of shallowing the chamber to unscroll the graft. An external force produced by digital compression of the globe may be required to increase posterior pressure and yield graft opening. Hypotonic or pre-phthisic eyes are also contraindicated to DMEK since ocular pressurization is required for correct graft attachment and surgical trauma may accelerate the process of bulbar atrophy.

Surgeons transitioning to the DMEK technique should preferably select cases of pseudophakic FECD with adequate corneal transparency, preserved anterior chamber anatomy and intact lens/iris diaphragm and avoid highly edematous corneas or with stromal haze that may impair visibility. $^{15,54}$ (Figure 6) 


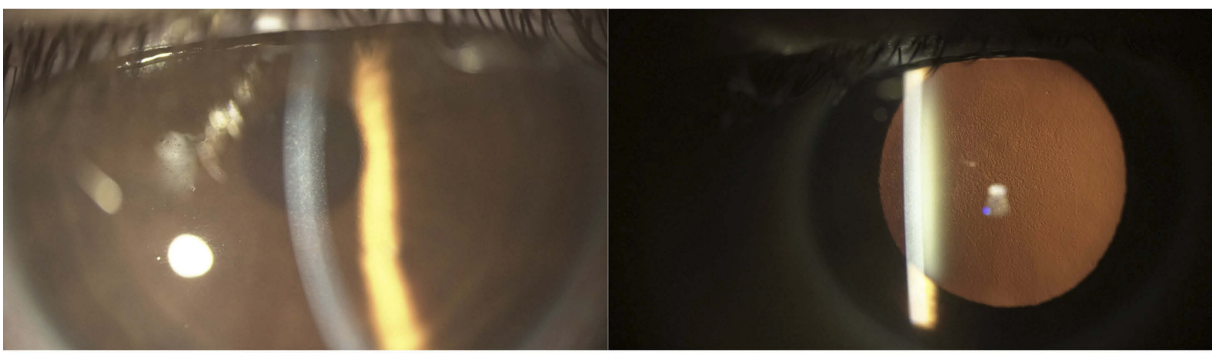

Figure 6 Fuchs endothelial dystrophy. Note the central guttae.

With the improvement of surgical skills, DMEK can be performed even in challenging situations such as grossly edematous corneas, aphakic eyes, anterior chamber lenses, tubes, synechiae, etc.

Salvaging a failed previous PK has been reported as viable with DMEK. In these cases, postoperative visual acuity may be limited by previous best-corrected vision (Figure 7).

The use of small aperture implants can minimize the impact of residual irregular astigmatism and has been shown to further improve vision in these patients. ${ }^{55}$ The combination of small aperture implants with DMEK may extend the indication of selective endothelial replacement of a failed PK even to irregular grafts. A higher graft detachment and rebubbling rates have been reported with DMEK after PK. ${ }^{56,57}$

Surgery is usually indicated whenever visual disturbances due to the endothelial disease become noticeable. It is important to note that low visual acuity with loss of Snellen lines may represent an advanced stage of the disease. Initial corneal edema, thickened Descemet's membrane and guttaes may produce light scatter, increase

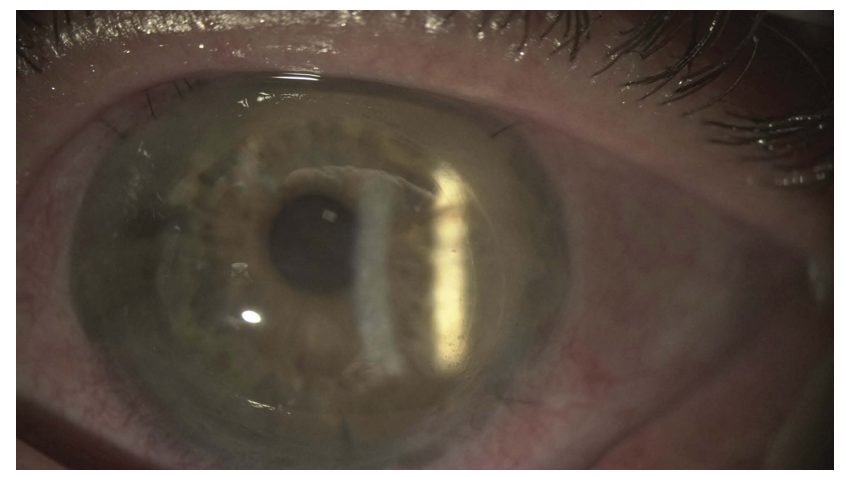

Figure 7 DMEK graft to rescue a failed PK. Note the DMEK graft edge inside the original graft-host junction.

Abbreviations: DMEK, descemet membrane endothelial keratoplasty; PK, penetrating keratoplasty. higher-order aberrations and decrease contrast sensitivity justifying an early indication of the procedure. ${ }^{58,59}$

There is no adequate cutoff point in pachymetry beyond which one can be certain of corneal decompensation. But, in general, corneas with central thickness above $650 \mu \mathrm{m}$ or with pachymetric worsening of more than 30 microns in 6 months are indication for endothelial transplant for most of the surgeons. It is important to consider the large overlap of pachymetric values between thin swollen corneas and thick but healthy corneas. ${ }^{60}$

Age, patient collaboration and postural alterations that impede the postoperative decubitus should be taken into account in the indication of surgery since the postoperative dorsal position is important to help graft attachment once the air/gas bubble is placed in the anterior chamber.

It is not uncommon patients with endothelial disease that also require cataract surgery. When there is concurrent endothelial disease and lens opacity, it can be challenging to assess the contribution for visual decrease of each individual disease. It is known that isolated cataract surgery before a DMEK may be feasible, cataract surgery in previously DMEK patients is also possible and, last, there is the possibility of combining the cataract surgery with DMEK in the same procedure. ${ }^{25,26}$ Interestingly, ECC has failed to predict which patients will develop corneal edema after cataract surgery, so there is no cut-off in ECC that could guide the surgeon in this decision. There is one variable that has been shown as a valid predictor of postoperative corneal decompensation. It is the epithelial valley measured in confocal microscopy. This is an indirect measure of epithelial edema, and it seems to be the predictive factor of corneal decompensation with greatest sensitivity and specificity. ${ }^{61}$ However, confocal microscopy access is not widespread limiting the clinical use of this. In practical terms, the presence of visual symptoms worse in the morning may indicate early signs of endothelial failure. CCT above $650 \mu \mathrm{m}$ is also likely to indicate corneal edema and endothelial failure. It is known that the chance of developing 
cataract after DMEK is influenced by surgical trauma, steroid use and patient's age. Patients over 50, even in the absence of lens opacity, may benefit from combined surgery because of the greater chance of needing cataract surgery shortly after DMEK. For younger patients with initial endothelial disease and a clear lens, phakic DMEK may be preferable. These patients need to be informed that cataract may develop shortly after the transplant and that cataract surgery might compromise the graft lifespan. ${ }^{62,63}$

\section{Conclusion}

DMEK represents the apex of what is currently understood by selective lamellar transplantation of the diseased layer of the cornea. The perfection of layer replacement is exemplified in this fascinating surgical technique, which allows fast recovery, excellent refractive results and low rejection rates in a safe procedure. This revolution in efficacy and prognosis introduced to cornea by DMEK transplantation may perhaps be compared to the transition of extracapsular cataract extraction era to the current phacoemulsification.

Although the learning curve for DMEK is long, more and more surgeons are adopting the technique. New perspectives for treatment of endothelial diseases like the descemetorhexis without donor cornea, the use of Rho-kinase inhibitors or the advent of cellular biology producing new endothelial cells without donors need are already realities and promise to further optimize the treatment of endothelial diseases.

\section{Disclosure}

The authors report no conflicts of interest in this work.

\section{References}

1. Melles GR, Eggink FA, Lander F, et al. A surgical technique for posterior lamellar keratoplasty. Cornea. 1998;17:618-626.

2. Terry MA, Ousley PJ. Deep lamellar endothelial keratoplasty in the first united states patients: early clinical results. Cornea. 2001;20:239243.

3. Terry MA, Ousley PJ. Small-incision Deep Lamellar Endothelial Keratoplasty (DLEK). Cornea. 2005;24:7.

4. Melles GRJ, Ong TS, Ververs B. Descemet Membrane Endothelial Keratoplasty (DMEK). Cornea. 2006;25:4.

5. Bahar I, Kaiserman I, McAllum P, Slomovic A, Rootman D. Comparison of posterior lamellar keratoplasty techniques to penetrating keratoplasty. Ophthalmology. 2008;115:1525-1533. doi:10.1016/j. ophtha.2008.02.010

6. Meter WSV. Eye Banking Statistical Report. Washington, DC: Eye Bank Association of America; 2016:2017.

7. Gorovoy MS. Descemet-stripping automated endothelial keratoplasty. Cornea. 2006;25:886-889. doi:10.1097/01.ico.0000214224.90743.01

8. Nanavaty MA, Wang X, Shortt AJ. Endothelial keratoplasty versus penetrating keratoplasty for Fuchs endothelial dystrophy. Cochrane Database Syst Rev. 2014. doi:10.1002/14651858.CD008420.pub3
9. Terry MA. Endothelial keratoplasty: why aren't we all doing descemet membrane endothelial keratoplasty? Cornea. 2012;31(5):469471. doi:10.1097/ICO.0b013e31823f8ee2

10. Liarakos VS, Tsatsos M, Satue M, Melles GRJ. Endothelial keratoplasty: is descemet membrane endothelial keratoplasty the way forward? Yes. Eye. 2017;31:1329-1332. doi:10.1038/ eye. 2017.52

11. Ciechanowski PP, Droutsas K, Baydoun L, Dirisamer M, Oellerich S, Melles GRJ. [Standardized Descemet membrane endothelial keratoplasty (DMEK): technique and latest results]. Der Ophthalmol. 2014;111:1041-1049. doi:10.1007/s00347-013-3014-8

12. Newman LR, DeMill DL, Zeidenweber DA, et al. Preloaded descemet membrane endothelial keratoplasty donor tissue: surgical technique and early clinical results. Cornea. 2018;37:981-986. doi:10.1097/ ICO.0000000000001646

13. Maier A-KB, Gundlach E, Schroeter J, et al. Influence of the difficulty of graft unfolding and attachment on the outcome in descemet membrane endothelial keratoplasty. Graefes Arch Clin Exp Ophthalmol. 2015;253:895-900. doi:10.1007/s00417-0152939-9

14. Sales CS, Straiko MD, Terry MA. Novel technique for rebubbling DMEK grafts at the slit lamp using intravenous extension tubing. Cornea. 2016;35:582-585. doi:10.1097/ICO.0000000000000755

15. Baydoun L, Ham L, Borderie V, et al. Endothelial survival after descemet membrane endothelial keratoplasty: effect of surgical indication and graft adherence status. JAMA Ophthalmol. 2015;133:1277. doi:10.1001/jamaophthalmol.2015.3064

16. Monnereau C, Quilendrino R, Dapena I, et al. Multicenter study of descemet membrane endothelial keratoplasty: first case series of 18 surgeons. JAMA Ophthalmol. 2014;132:1192-1198. doi:10.1001/ jamaophthalmol.2014.1710

17. Stanzel TP, Ersoy L, Sansanayudh W, et al. Immediate postoperative intraocular pressure changes after anterior chamber air fill in descemet membrane endothelial keratoplasty. Cornea. 2016;35:14-19. doi:10.1097/ICO.0000000000000669

18. Schmeckenbächer N, Frings A, Kruse FE, Tourtas T. Role of initial intraocular pressure in graft adhesion after descemet membrane endothelial keratoplasty. Cornea. 2017;36:7-10. doi:10.1097/ ICO.0000000000001055

19. Yoeruek E, Bartz-Schmidt K-U. Secondary descemet membrane endothelial keratoplasty after failed primary descemet membrane endothelial keratoplasty: clinical results. Cornea. 2013;32:14141417. doi:10.1097/ICO.0b013e31828321c1

20. Rodríguez-Calvo-de-Mora M, Quilendrino R, Ham L, et al. Clinical outcome of 500 consecutive cases undergoing descemet's membrane endothelial keratoplasty. Ophthalmology. 2015;122:464-470. doi:10.1016/j.ophtha.2014.09.004

21. Heinzelmann S, Böhringer D, Eberwein P, Reinhard T, Maier P. Outcomes of descemet membrane endothelial keratoplasty, descemet stripping automated endothelial keratoplasty and penetrating keratoplasty from a single centre study. Graefes Arch Clin Exp Ophthalmol. 2016;254:515-522. doi:10.1007/s00417-015-3248-z

22. Schlögl A, Tourtas T, Kruse FE, Weller JM. Long-term clinical outcome after descemet membrane endothelial keratoplasty. Am J Ophthalmol. 2016;169:218-226. doi:10.1016/j.ajo.2016.07.002

23. Anshu A, Price MO, Price FW Jr. Risk of corneal transplant rejection significantly reduced with descemet's membrane endothelial keratoplasty. Ophthalmology. 2012;119:536-540.

24. Price MO, Scanameo A, Feng MT, Price FW Jr Descemet's membrane endothelial keratoplasty: risk of immunologic rejection episodes after discontinuing topical corticosteroids. Ophthalmology. 2016;123:1232-1236. doi:10.1016/j.ophtha.2016.02.001

25. Parker J, Dirisamer M, Naveiras M, et al. Outcomes of descemet membrane endothelial keratoplasty in phakic eyes. $J$ Cataract Refract Surg. 2012;38:871-877. doi:10.1016/j.jcrs.2011.11.038 
26. Chaurasia S, Price FW, Gunderson L, Price MO. Descemet's membrane endothelial keratoplasty: clinical results of single versus triple procedures (combined with cataract surgery). Ophthalmology. 2014;121:454-458. doi:10.1016/j.ophtha.2013.09.032

27. Kocaba V, Damour O, Auxenfans C, Burillon C. Descemet's membrane endothelial keratoplasty. Indication, technique chirurgicale, gestion postopératoire et revue de la littérature. $J$ Fr Ophtalmol. 2018;41:368-381. doi:10.1016/j.jfo.2017.12.005

28. Li S, Liu L, Wang W, et al. Efficacy and safety of descemet's membrane endothelial keratoplasty versus descemet's stripping endothelial keratoplasty: a systematic review and meta-analysis. PLoS One. 2017;12:e0182275. doi:10.1371/journal.pone.0182275

29. Deng SX, Lee WB, Hammersmith KM, et al. Descemet membrane endothelial keratoplasty: safety and outcomes. Ophthalmology. 2018;125:295-310. doi:10.1016/j.ophtha.2017.08.015

30. Stuart AJ, Romano V, Virgili G, Shortt AJ. Descemet's membrane endothelial keratoplasty (DMEK) versus descemet's stripping automated endothelial keratoplasty (DSAEK) for corneal endothelial failure. Cochrane Database Syst Rev. 2018. doi:10.1002/14651858. CD012097.pub2

31. Zhu L, Zha Y, Cai J, Zhang Y. Descemet stripping automated endothelial keratoplasty versus descemet membrane endothelial keratoplasty: a meta-analysis. Int Ophthalmol. 2018;38:897-905. doi:10.1007/s10792-017-0533-3

32. Marques RE, Guerra PS, Sousa DC, Gonçalves AI, Quintas AM, Rodrigues W. DMEK versus DSAEK for Fuchs' Endothelial dystrophy: a meta-analysis. Eur J Ophthalmol. 2019;29:15-22. doi:10.1177/ 1120672118757431

33. Dapena I, Ham L, Melles GR. Endothelial keratoplasty: DSEK/ DSAEK or DMEK - the thinner the better? Curr Opin Ophthalmol. 2009;20:299-307. doi:10.1097/ICU.0b013e32832b8d 18

34. Droutsas K, Giallouros E, Melles GRJ, Chatzistefanou K, Sekundo W. Descemet membrane endothelial keratoplasty: learning curve of a single surgeon. Cornea. 2013;32:5.

35. Dapena I, Ham L, Droutsas K, van Dijk K, Moutsouris K, Melles GRJ. Learning curve in descemet's membrane endothelial keratoplasty: first series of 135 consecutive cases. Ophthalmology. 2011;118:2147-2154. doi:10.1016/j.ophtha.2011.03.037

36. Guerra FP, Anshu A, Price MO, Giebel AW, Price FW. Descemet's membrane endothelial keratoplasty: prospective study of 1-year visual outcomes, graft survival, and endothelial cell loss. Ophthalmology. 2011;118:2368-2373. doi:10.1016/j.ophtha.2011.06.002

37. Heindl LM, Riss S, Adler W, Bucher F, Hos D, Cursiefen C. Split cornea transplantation: relationship between storage time of split donor tissue and outcome. Ophthalmology. 2013;120:899-907. doi:10.1016/j.ophtha.2012.11.012

38. van Dijk K, Ham L, Tse WHW, et al. Near complete visual recovery and refractive stability in modern corneal transplantation: descemet membrane endothelial keratoplasty (DMEK). Cont Lens Anterior Eye. 2013;36:13-21. doi:10.1016/j.clae.2012.10.066

39. Pavlovic I, Shajari M, Herrmann E, Schmack I, Lencova A, Kohnen T. Meta-analysis of postoperative outcome parameters comparing descemet membrane endothelial keratoplasty versus descemet stripping automated endothelial keratoplasty. Cornea. 2017;36:1445-1451. doi:10.1097/ICO.0000000000001384

40. Goren MB. Meta-analysis of descemet membrane endothelial keratoplasty versus descemet stripping automated endothelial keratoplasty postoperative visual outcomes. Cornea. 2018;37:e35. doi:10.1097/ ICO.0000000000001561

41. Ham L, Dapena I, Moutsouris K, et al. Refractive change and stability after descemet membrane endothelial keratoplasty. Effect of corneal dehydration-induced hyperopic shift on intraocular lens power calculation. J Cataract Refract Surg. 2011;37:1455-1464. doi:10.1016/j.jcrs.2011.02.033
42. Schoenberg ED, Price FW, Miller J, McKee Y, Price MO. Refractive outcomes of descemet membrane endothelial keratoplasty triple procedures (combined with cataract surgery). J Cataract Refract Surg. 2015;41:1182-1189. doi:10.1016/j.jcrs.2014.09.042

43. Alnawaiseh M, Rosentreter A, Eter N, Zumhagen L. Changes in corneal refractive power for patients with Fuchs endothelial dystrophy after DMEK. Cornea. 2016;35:1073-1077. doi:10.1097/ ICO.0000000000000842

44. Tong CM, Baydoun L, Melles GRJ. Descemet membrane endothelial keratoplasty and refractive surgery:. Curr Opin Ophthalmol. 2017;28:316-325. doi:10.1097/ICU.0000000000000380

45. Pereira NC, Diniz ER, Ghanem RC, et al. Descemet membrane endothelial keratoplasty in multifocal pseudophakic eyes. Arq Bras Oftalmol. 2018;81. doi:10.5935/0004-2749.20180039

46. Satue M, Idoipe M, Gavin A, et al. Early changes in visual quality and corneal structure after DMEK: does DMEK approach optical quality of a healthy Cornea? $J$ Ophthalmol. 2018;2018:1-8. doi: $10.1155 / 2018 / 2012560$

47. Lam FC, Baydoun L, Dirisamer M, Lie J, Dapena I, Melles GRJ. Hemidescemet membrane endothelial keratoplasty transplantation: a potential method for increasing the pool of endothelial graft tissue. JAMA Ophthalmol. 2014;132:1469-1473. doi:10.1001/jamaophthalmol.2014.3 328

48. Müller TM, Lavy I, Baydoun L, Lie JT, Dapena I, Melles GRJ. Case report of quarter-descemet membrane endothelial keratoplasty for Fuchs endothelial dystrophy. Cornea. 2017;36:104-107. doi:10.1097/ICO.0000000000001008

49. Baydoun L, Zygoura V, Hsien S, et al. Clinical feasibility of using multiple grafts from a single donor for quarter-DMEK. Acta Ophthalmol (Copenh). 2018;96:e656-e658. doi:10.1111/ aos. 13720

50. Birbal RS, Hsien S, Zygoura V, et al. Outcomes of hemi-descemet membrane endothelial keratoplasty for Fuchs endothelial corneal dystrophy. Cornea. 2018;37:854-858. doi:10.1097/ICO.00000000 00001578

51. Zygoura V, Baydoun L, Ham L, et al. Quarter-descemet membrane endothelial keratoplasty (Quarter-DMEK) for Fuchs endothelial corneal dystrophy: 6 months clinical outcome. $\mathrm{Br} J$ Ophthalmol. 2018;102:1425-1430. doi:10.1136/bjophthalmol-2017-311398

52. Zygoura V, Lavy I, Verdijk RM, et al. Atypical presentation of iridocorneal endothelial syndrome with band keratopathy but no corneal edema managed with descemet membrane endothelial keratoplasty. Cornea. 2018:37:1064-1066. doi:10.1097/ICO.0000000000001593

53. Pierné K, Panthier C, Courtin R, et al. Descemet membrane endothelial keratoplasty after failed penetrating keratoplasty. Cornea. 2019;38:280-284. doi:10.1097/ICO.0000000000001834

54. O'Brien PD, Lake DB, Saw VP, Rostron CK, Dart JK, Allan BD. Endothelial keratoplasty: case selection in the learning curve. Cornea. 2008;27:1114-1118. doi:10.1097/ICO.0b013e318180e58b

55. Trindade BLC, Trindade FC, Trindade CLC, Santhiago MR. Phacoemulsification with intraocular pinhole implantation associated with descemet membrane endothelial keratoplasty to treat failed fullthickness graft with dense cataract. $J$ Cataract Refract Surg. 2018;44:1280-1283. doi:10.1016/j.jcrs.2018.06.047

56. Liarakos VS, Ham L, Dapena I, et al. Endothelial keratoplasty for bullous keratopathy in eyes with an anterior chamber intraocular lens. J Cataract Refract Surg. 2013;39:1835-1845. doi:10.1016/j.jcrs.2013.05.045

57. Liarakos VS, Satué M, Livny E, et al. Descemet membrane endothelial keratoplasty for a decompensated penetrating keratoplasty graft in the presence of a long glaucoma tube. Cornea. 2015;34:1613-1616. doi:10.1097/ICO.0000000000000631

58. Keane MC, Galettis RA, Mills RAD, Coster DJ, Williams KA. Registry fCttACG. A comparison of endothelial and penetrating keratoplasty outcomes following failed penetrating keratoplasty: a registry study. Br J Ophthalmol. 2016;100:1569-1575. doi:10.1136/ bjophthalmol-2015-307792 
59. Oie Y, Watanabe S, Nishida K. Evaluation of visual quality in patients with Fuchs endothelial corneal dystrophy. Cornea. 2016;35 Suppl 1:S55-S58. doi:10.1097/ICO.0000000000000994

60. Kwon RO, Price MO, Price FW, Ambrósio R, Belin MW. Pentacam characterization of corneas with Fuchs dystrophy treated with descemet membrane endothelial keratoplasty. J Cataract Refract Surg. 2010;26:972-979. doi:10.3928/1081597X-20100212-08

61. van Cleynenbreugel H, Remeijer L, Hillenaar T. Cataract surgery in patients with Fuchs' Endothelial corneal dystrophy: when to consider a triple procedure. Ophthalmology. 2014;121:445-453. doi:10.1016/j. ophtha.2013.09.047
62. Price MO, Price DA, Fairchild KM, Price FW. Rate and risk factors for cataract formation and extraction after descemet stripping endothelial keratoplasty. $\mathrm{Br} J$ Ophthalmol. 2010;94:1468-1471. doi:10.1136/bjo.2009.175174

63. Burkhart ZN, Feng MT, Price FW, Price MO. One-year outcomes in eyes remaining phakic after descemet membrane endothelial keratoplasty. J Cataract Refract Surg. 2014;40:430-434. doi:10.1016/j. jcrs.2013.08.047

\section{Publish your work in this journal}

Clinical Ophthalmology is an international, peer-reviewed journal covering all subspecialties within ophthalmology. Key topics include: Optometry; Visual science; Pharmacology and drug therapy in eye diseases; Basic Sciences; Primary and Secondary eye care; Patient Safety and Quality of Care Improvements. This journal is indexed on PubMed

Submit your manuscript here: https://www.dovepress.com/clinical-ophthalmology-journal
Central and CAS, and is the official journal of The Society of Clinical Ophthalmology (SCO). The manuscript management system is completely online and includes a very quick and fair peer-review system, which is all easy to use. Visit http://www.dovepress.com/ testimonials.php to read real quotes from published authors. 